\title{
Do we need to use nitric oxide in preterm babies in developing countries?
}

\author{
Pankaj Garg1
}

\begin{abstract}
Neonatal care in developing nations is advancing rapidly. There is an increasing tendency to include nitric oxide in the therapeutic armamentarium. But the opinion regarding its use remains divided among neonatologists even in the western world [1]. Nitric oxide has an established role in the management of persistent pulmonary hypertension in term neonates. However, the use of nitric oxide in preterm neonates has been controversial and the Cochrane review updated in 2001 did not give conclusive answers. There have been adequately powered multi-centre trials recently on the issue, planned to resolve the controversy. The present communication highlights the salient features and conclusions drawn from these trials.
\end{abstract}

The survival of preterm and extremely low birthweight neonates has increased dramatically [2]. There have been dramatic responses to exogenous surfactant treatment. However, a subset of these neonates with hyaline membrane disease may have suboptimal response because of severe pulmonary hypertension $[3,4]$. Inhaled nitric oxide may be beneficial for them by dilating the pulmonary vasculature, improving ventilation/perfusion mismatch, and decreasing the pulmonary inflammatory response [5,6]. Inhaled nitric oxide has an established role for the management of persistent pulmonary hypertension in term neonates [7]. Its role in preterm neonates has been controversial and its safety and efficacy have been questioned [8,9]. Meta-analysis of randomised trials done up to 1999 did not give conclusive answers [10]. Studies done in the past were underpowered and had methodological limitations such as entry criteria, drug concentration, and duration and definition of response. To resolve this controversy recent randomised trials have been conducted. I searched the MEDLINE (PubMed), CINAHL, EMBASE, Cochrane-controlled trials and did a hand-search of major paediatric and neonatology journals for randomised trials pertaining to the use of inhaled nitric oxide in preterm neonates from 1996 onwards. This communication discusses three recently concluded large multi-centric trials and summarises the results of other randomised trials:

1. Preemie Inhaled Nitric Oxide Group (USA): This was a multi-centre, randomised, blinded controlled trial from 16 centres of the National Institute of Child Health and Human Development (NICHD) Neonatal Research Network [11]. A dedicated telephone system was used for randomisation. Infants were stratified according to the centre and birthweight using a permutated block design method. The primary hypothesis was that administration of inhaled nitric oxide would reduce the incidence of bronchopulmonary dysplasia (BPD) or death in neonates less than 34 weeks gestation and birthweight between $401-1500 \mathrm{~g}$. The group recruited 420 infants less than 34 weeks $(401-1500 \mathrm{~g}, 47 \%<750 \mathrm{~g})$ at $4-120$ hours of age with oxygenation index $\geq 5$ followed by 7.5 and having received at least one dose of surfactant 4 hours before meeting the criteria. The study was terminated when two thirds of the infants reached study end-points of death, discharge or 1 year corrected age due to higher incidence of intraventricular haemorrhage (IVH) noted in the inhaled nitric oxide (iNO) group at interim analysis. Infants were randomised to receive $5 \mathrm{ppm}$ iNO or simulated flow by an unblinded respiratory therapist with concentration increased to maximum of $10 \mathrm{ppm}$ if there was a partial response $\left(\mathrm{PaO}_{2}\right.$ increases between $\left.10-20 \mathrm{~mm} \mathrm{Hg}\right)$. The study gas was weaned after 10-14 hours if $\mathrm{PaO}_{2}$ was $>50$ mmHg and saturation was more than $90 \%$. The maximum duration the gas could be given was 14 days (concentration limited to $\leq 1 \mathrm{ppm}$ if given for $>10$ days).

Safety monitoring was ensured by using frequent measurement of methaemoglobin concentrations and continuous nitrogen dioxide measurements. Both the study and control groups were comparable in terms of baseline characteristics (mean weight $840 \mathrm{~g}$, mean gestational age 26 weeks, about $70 \%$ antenatal steroid use) and status at the time of randomisation (mean age 26 hours, mean oxygenation index 23). There was no difference for either primary or secondary outcomes between the groups. The incidence of BPD or death was $80 \%$ in the iNO group versus $82 \%$ in the placebo group (relative risk, RR 0.97; 95\% CI 0.86-1.08; $\mathrm{p}=0.26$ ). Similarly, there was no difference for severe IVH, oxygen use, physiological BPD, length of hospitalisation, duration of ventilation, air leaks and threshold retinopathy of prematurity. There was a short term improvement in oxygenation in the iNO group with 5 ppm which does not persist with doubling of the dose. However, post hoc analysis after stratification of birthweight $(<1000 \mathrm{~g}$ and $>1000 \mathrm{~g})$, type of ventilation and oxygenation index (OI) for severity of illness (OI $<$ 17 , or $\mathrm{OI}>17$ ) revealed some striking findings. In the birthweight category $<1000 \mathrm{~g}$ death or severe IVH was more in the group given iNO $(62 \%$ vs $48 \%$, RR 1.28 , $95 \%$ CI $1.06-1.54 ; \mathrm{P}=0.01 ; 43 \%$ vs $33 \%$, RR $1.40,95 \%$ CI $1.03-1.88 ; \mathrm{P}=0.03$ respectively). Infants $>1000 \mathrm{~g}$ had

${ }^{1}$ Neonatal Registrar, Royal Hospital for Women, University of New South Wales, Randwick, NSW, Australia, 2031; e-mail: <GargP@sesiahs.nsw.gov.au>, <pankajparul8@rediffmail.com>. (Conflict of interest: none declared). 
lower rates of death or BPD (50\% vs $69 \%$; RR $0.72,95 \%$ CI 0.54-0.96; $\mathrm{P}=0.03$ ).

The findings from this well conducted high quality study show that (a) iNO does not alter the mortality or morbidity profile of preterm $<1500 \mathrm{~g}$ and $<34$ weeks' gestation, (b) increase in the incidence of IVH in infants $<1000$ g may reflect production of biologically toxic byproducts and indicates caution for use in this group. However, it is not clear from the study whether IVH occurred prior to exposure of iNO or after it as Ultrasound cranium was done at $28 \pm 3$ days in the study, and (c) doubling the dose of inhaled nitric oxide to $10 \mathrm{ppm}$ does not offer any advantage even in short terms.

\section{INNOVA Multi-centre Trial (the UK and the Republic} of Ireland): This trial was conducted in 15 neonatal units of the UK and the Republic of Ireland [12]. The study could only recruit just over half of its recruitment target (108 infants as against an expected sample size of 200 needed to power the study). The main reason given for this was physician characteristics, as many clinicians were convinced regarding the perceived benefits of iNO (75 eligible preterm received nitric oxide outside the study trial). Infants $<34$ weeks gestation and less than 28 days requiring ventilation were randomised to receive either iNO starting from 5 ppm increased to a maximum of 40 ppm, and then maintained at the lowest effective dose or placebo. Three principal diagnostic categories were used at the entry of the trial. Acute preterm lung disease presenting with lung disease immediately after birth and randomised at $\leq 3$ days of age, chronic preterm lung disease presenting with lung disease immediately after birth and randomised for continuous problems after 3 days of age and the "other" group which included preterm infants who developed lung disease after recovering from an initial respiratory problem. If there was no response, then $5 \mathrm{ppm}$ iNO was continued for 12 hours. No crossover was allowed between the groups.

The major feature of this study was that outcomes were assessed both in the short term as well as the long term at 1 year corrected age. The authors also did a cost analysis of the inhaled nitric oxide and the mean costs incurred at 1 year corrected age, using a series of crosssectional questionnaires sent to the parents (unit costs for the hospital services were taken from the National Health Service, NHS reference costs database). There was no evidence of an effect of iNO on primary outcomes: death or severe disability at 1 year corrected age (RR 0.99; $95 \%$ CI 0.76-1.29); death or supplemental oxygen on expected date of delivery (RR 0.84 ; 95\% CI 0.68-1.02) and death or supplemental oxygen at 36 weeks postconceptional age (RR 0.98; 95\% CI 0.87-1.17). There was trend for infants allocated to the iNO group to spend more time on the ventilator (log rank 3.6) and on supplemental oxygen (log rank 3.5). This pattern reflected predominantly the infants who died. Mean total costs at 1 year corrected age were significantly more in the iNO group, partly because of the costs of the gas but mainly because of the difference in initial hospitalisation costs. The unit cost for inhaled nitric oxide in this study was $£ 33$ per hour, which was the average cost charged to NHS providers. Even though the study was not adequately powered, it concluded that iNO cannot be recommended for preterm infants with severe respiratory failure.

3. Franco-Belgium Collaborative NO Trial Group: Ten tertiary perinatal centres in France and Belgium recruited 860 infants $<32$ weeks of gestation and receiving surfactant within first 2 hours of birth [13]. Randomisation was blinded only till 6 hours of age. Subsequently, if the infants had hypoxaemic respiratory failure as defined by the need for mechanical ventilation with fraction of inspired oxygen $>40 \%$ and arterial-alveolar ratio, a/A $<0.22$ the allocation was disclosed as control or iNO group (starting dose of $5 \mathrm{ppm}$ increased to a maximum of 10 ppm). Mean gestational age was about 25.7 weeks and $31 \%$ infants were $<1000 \mathrm{~g}$. Mean oxygenation index was 14.6 for iNO versus 12 for controls. The major caveats of this trial was the use of an open label iNO in newborns with refractory hypoxaemia $\left(\mathrm{PaO}_{2}<50 \%\right.$ on $100 \%$ oxygen) as per the ruling of the French drug authority law, which recommends iNO use in any newborn with refractory hypoxaemia (20 eligible infants at $<6$ hours of age, 20 in iNO group and 28 of control group). This decreased the power of the study.

To establish the safety of inhaled nitric oxide the authors used multivariate stepwise logistic regression analysis and evaluated the risk factors of IVH, brain lesions (IVH or periventricular leucomalacia, PVL) or death and BPD at 28 days of life. Nitric oxide therapy was included in all models. There were no differences in primary outcome defined as intact survival at 28 days (61.4\% iNO vs $61.1 \%$; $\mathrm{p}=0.943)$. There were no differences in secondary outcomes also (necrotising enterocolitis $8 \%$ vs $6 \%$, patent ductus arteriosus $34 \%$ vs $37 \%$, mortality $41 \%$ vs $31 \%$ and infants with respiratory support on day $2844 \%$ vs $47 \%$ between iNO groups and controls respectively). No differences were established for the occurrence of IVH before onset of nitric oxide or on day 7 of life. Inhaled nitric oxide was not an independent risk factor for the combined risk of death or brain lesions (adjusted RR 1.29, 95\% CI 0.796-2.12) and BPD (adjusted RR 0.653; 95\% CI 0.403-1.057). In fact, $45 \%$ of infants receiving iNO had a positive response (defined as increase in $\mathrm{a} / \mathrm{A}>0.22$ ).

The study concluded that inhaled nitric oxide is safe in preterm neonates but did not affect outcomes. To further substantiate the safety of inhaled nitric oxide in the same group of neonates in another parallel study, the authors also assessed malondialdehyde (MDA) concentrations as an oxidative stress marker and total plasmatic glutathione (GSH), intraerythrocyte GSH peroxidase and GSH reductase activities as antioxidant defenses. After 24 hours the rise of MDA was blunted in the iNO group. Conversely, GSH was more stable in the iNO group. On day 28 oxygen dependence was linked with a higher 


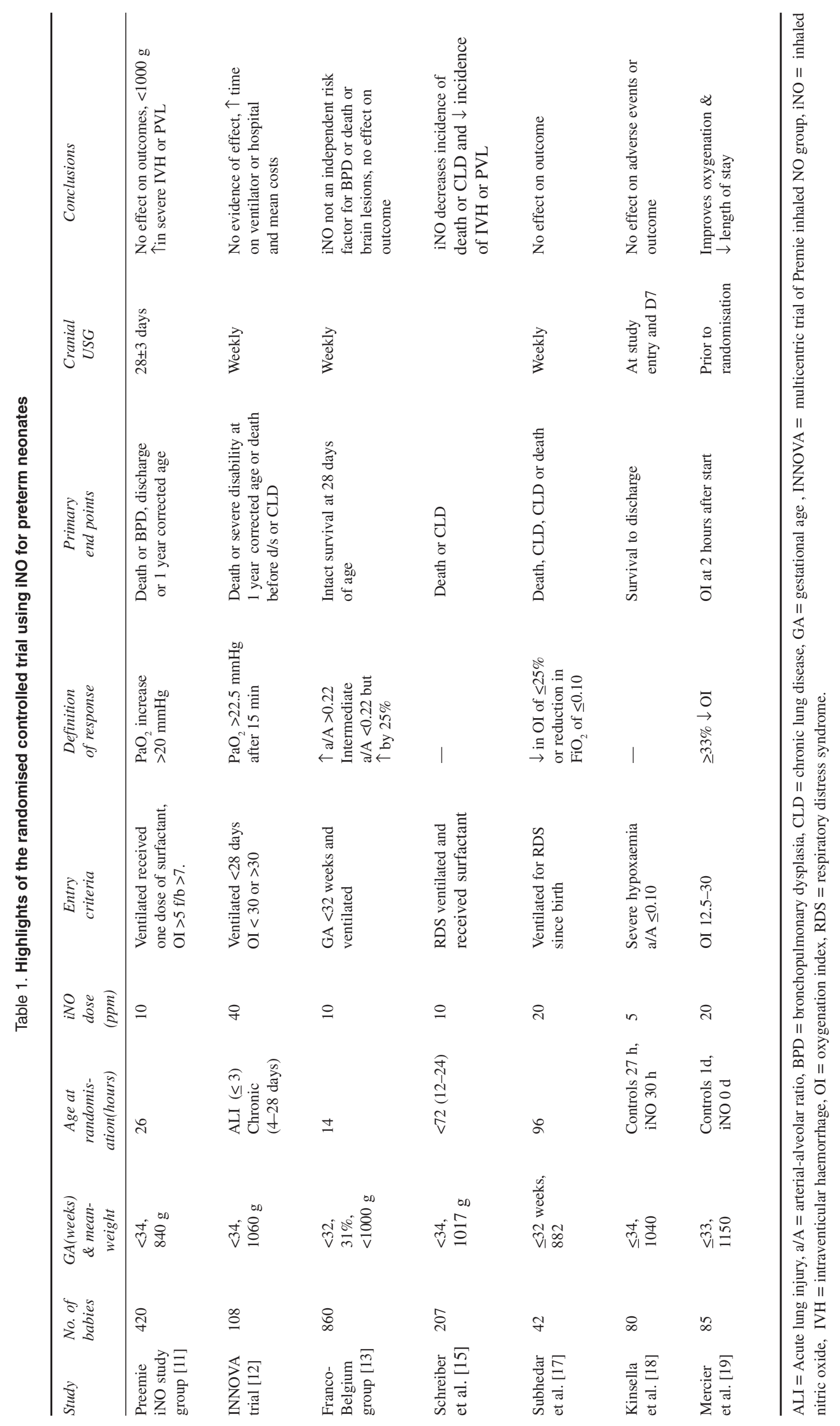


increase in MDA as was the risk of death, whereas IVH was associated with a higher initial drop in GSH. The study showed that early low dose iNO in hypoxaemic preterm neonates improves oxidative balance, and seems to be clinically beneficial up to day 28 of life [14].

4. Another recent randomised double-blind controlled trial is a single centre trial on 207 premature neonates less than 34 weeks of gestation to iNO $10 \mathrm{ppm}$ on the first day followed by 5 ppm for 6 days or inhaled oxygen placebo for 7 days. The authors reported a lower incidence of death or chronic lung disease in the group given inhaled nitric oxide $(48.6 \%$ vs $63.7 \%$, RR 0.76 ; $95 \%$ CI $0.60-0.97$; $\mathrm{P}=0.03)$, as well as a lower incidence of severe IVH and PVL (12.4\% vs 23.5\%; RR 0.53, 95\% CI 0.28-0.98; $\mathrm{P}=0.04)$. This is the only trial which has shown a beneficial role of inhaled nitric oxide in preterm neonates.

However, the major concerns regarding this trial are that the placebo group had very high mortality $(63.7 \%$ vs 48.6) and the use of antenatal steroids is only about $50 \%$. Also, the enrolled neonates were much less sicker than those in other trials (median OI 6.94) [15]. The authors have also published their data on 138 children followed up longitudinally till 2 years corrected age. Inhaled nitric oxide group were shown to have significantly less abnormal neurodevelopmental outcomes (24\% vs $46 \%$; RR, 0.53 ; $95 \%$ of CI $0.33-0.87 ; \mathrm{p}=0.01)$. This difference was independent of birthweight, sex, presence or absence of chronic lung disease (CLD) and severe IVH or PVL. This improvement was shown primarily due to a $47 \%$ decrease in the risk of cognitive impairment $(\mathrm{p}=0.03)$ [16].

5. There are three other small randomised trials for which pooled meta-analysis of 210 infants $<33$ weeks of gestation did not reveal any difference in death $(39.6 \%$ iNO vs $40.4 \%, \mathrm{p}=0.91$ ), death or CLD (OR 0.77, 95\% CI $0.41-1.45: \mathrm{p}=0.39)$ or IVH (OR $1.37,95 \%$ CI 0.69 2.74, $\mathrm{P}=0.33$ ) [9].

A preliminary meta-analysis of all available studies of iNO in preterm infants published up to March 2005 suggested that although iNO may reduce death or BPD at 36 weeks postconceptional age, there may be an increase in the occurrence of severe IVH or PVL [20]. Pathophysiological aspects of inhaled nitric oxide on the developing central nervous system are not clear [21, 22]. Furthermore, some animal model studies have shown a beneficial effect of low doses of nitric oxide given for weeks on the development of respiratory system including effects on angiogenesis, maturation of lung parenchyma and airway smooth muscle [23].

\section{Conclusions}

Uncertainty surrounds the use of inhaled nitric oxide in preterm neonates. There is no evidence to recommend the routine rescue use of inhaled nitric oxide in preterm infants with hypoxaemic respiratory failure. Pre-treatment oxygenation index and timing may be factors determining whether inhaled nitric oxide will produce beneficial results. Examining the evidence and the prohibitive costs of inhaled nitric oxide, it does not seem to be a feasible option for the introduction of iNO in developing nations.

\section{References}

1. Field DJ. Nitric oxide - still no consensus. Early Human Development 2005; 81: 1-4.

2. St John EB, Carlo WA. Respiratory distress syndrome in very low birthweight infants: changes in management and outcomes observed by the NICHD neonatal research network. Seminars in Perinatology 2003; 27: 288-92.

3. Charafeddine L, D' Angio CT, Phelps DL. Atypical chronic lung disease in neonates. Pediatrics 1999; 103: 759-65.

4. Halliday H, Hirschfeld S, Riggs T, Leibman J, Fanaroff A, Bormuth C. Respiratory distress syndrome: echocardiographic assessment of cardiovascular function and pulmonary vascular resistance. Pediatrics 1977; 60: 444-9.

5. Frostell C, Fratacci MD, Wain JC, Jones R, Zapol WM. Inhaled nitric oxide: a selective pulmonary vasodilator reversing hypoxic pulmonary vasoconstriction. Circulation 1991; 83: 2038-47.

6. Kinsella JP, Parker TA, Galan H, Sheridan BC, Halbower $\mathrm{AC}$, et al. Effects of inhaled nitric oxide on pulmonary edema and lung neutrophil accumulation in severe experimental hyaline membrane disease. Pediatric Research 1997; 41: 457-63.

7. Finer NN, Barrington KJ. Nitric oxide for respiratory failure in infants born at or near term. Cochrane Database Systematic Reviews 2000; 2: CD000399.

8. Barrington KJ, Finer NN. Inhaled nitric oxide for respiratory failure in preterm infants. In: The Cochrane Library. Issue 4. Chi Chester, United Kingdom: John Wiley \& Sons, 2003.

9. Saugstad OD. Inhaled nitric oxide for preterm infants still an experimental therapy. Lancet 1999; 354: 1047-8.

10. Hoehn T, Krause MF, Bührer C. Inhaled nitric oxide in premature infants - a meta-analysis. Journal of Perinatal Medicine 2000; 28: 7-13.

11. Van Meurs KP, Wright LL, Ehrenkranz RA, Lemons JA, Ball MB, et al. Inhaled nitric oxide for premature infants with severe respiratory failure. New England Journal of Medicine 2005; 353: 13-22.

12. Field D, Elbourne D, Truesdale A, Grieve R, Hardy P, et al. Neonatal ventilation with inhaled nitric oxide versus ventilatory support without inhaled nitric oxide for preterm infants with severe respiratory failure: The INNOVO multicentre randomised controlled trial (ISRCTN 17821339). Pediatrics 2005; 115: 926-35.

13. Hascoet JM, Fresson J, Claris O, Hamon I, Lombet J, et al. The safety and efficacy of nitric oxide therapy in premature infants. The Journal of Pediatrics 2005; 146: 318-23.

14. Hamon I, Freeson J, Nicolas MB, Buchweiller MC, Franck $\mathrm{P}$, et al. Early inhaled nitric oxide improves oxidative 
balance in very preterm infants. Pediatric Research 2005; 57: 637-43.

15. Schreiber MD, Gin-Mestan K, Marks JD, Huo D, Lee G, et al. Inhaled nitric oxide in premature infants with the respiratory distress syndrome. New England Journal of Medicine 2003; 349: 2099-107.

16. Mestan KK, Marks JD, Hecox K, Huo D, Schreiber MD. Neurodevelpmental outcomes of premature infants treated with inhaled nitric oxide. New England Journal of Medicine 2005; 353: 23-32.

17. Subhedar NV, Ryan SW, Shaw NJ. Open randomised controlled trial of inhaled nitric oxide and early dexamethasone in high-risk preterm infants. Archives Diseases of Childhood Fetal Neonatal 1997; 7: 185-90.

18. Kinsella JP, Walsh WF, Bose CL, Gerstmann DR, Labella $\mathrm{JJ}$, et al. Inhaled nitric oxide in premature neonates with severe hypoxemic respiratory failure: a randomised controlled trial. Lancet 1999; 354: 1061-5.
19. The Franco-Belgium collaborative NO trial group. Early compared with delayed inhaled nitric oxide in moderately hypoxaemic neonates with respiratory failure: a randomised controlled trial. Lancet 1999; 354: 1066-71.

20. Finer NN. Inhaled nitric oxide for preterm infants: A therapy in search of an indication? The search continues. Journal of Pediatrics 2005; 146: 301-2.

21. Martin RJ. Nitric oxide for preemies - not so fast. New England Journal of Medicine 2003; 349: 2157-9.

22. Martin RJ, Walsh MC. Inhaled nitric oxide for preterm infants-who benefits? New England Journal of Medicine 2005; 353: 82-4.

23. McCurnin DC, Pierce RA, Chang LY, Gibson LL, Osborne-Lawrence S, et al. Inhaled nitric oxide improves early pulmonary function and modifies lung growth and elastin deposition in a baboon model of neonatal chronic lung disease. American Journal of Physiology-Lung Cellullar and Molecular Physiology 2005; 288: 450-9. 